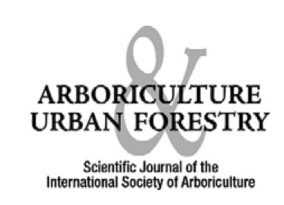

\title{
Methodology for Spatial Analysis of Municipal Street Tree Benefits
}

\author{
F.D. Cowett
}

\begin{abstract}
Street trees comprise a fraction of the urban forest; however, due to their public function, the benefits they provide to urban residents have received particular attention from researchers. Spatial analyses of street tree benefits have been based on street tree counts that do not account for differences in tree species and size that in turn impact leaf surface area from which most benefits are derived. The United States Forest Service's i-Tree Streets software program quantifies street tree benefits and does account for differences in tree species and size, but is not a Geographic Information Systems program and does not facilitate the spatial analysis of street tree benefits. This paper proposes a methodology for analyzing the spatial distribution of street tree benefits employing measures based on i-Tree Streets. Providence, Rhode Island, U.S., serves as a case study. Key Words. Benefits; GIS; i-Tree; Services; Spatial Analysis; Street Trees.
\end{abstract}

Research has shown urban trees to provide benefits to urban residents. These benefits include but are not limited to improved air quality (Cavanagh et al. 2009), mitigation of heat island effect (Lynn et al. 2009), increased real estate values (Anderson and Cordell 1988), stormwater reduction (Xiao et al. 1998), a greater sense of community (Kuo 2003), and encouragement of physical activity (Giles-Corti and Donovan 2003). Because of these benefits, the spatial distribution of urban trees is of interest. For example, researchers have examined whether urban trees are distributed evenly in urban areas, and if not, whether an uneven distribution is associated with socioeconomic factors, such as income, education, and race. In most of these studies, tree canopy cover was selected as the dependent variable. This choice made sense because many benefits provided by trees, particularly those associated with ecosystem services, are proportional to leaf surface area (McPherson and Rowntree 1989), while canopy cover, the percentage of ground area covered by the vertical projection of tree crowns (Jennings et al. 1999), is a measure related to leaf surface area. Thus, Talarcheck (1990), Iverson and Cook (2000), Escobedo et al. (2006), Luck et al. (2009), and Pham et al. (2012) found a positive relationship between wealth and canopy cover; Heynen et al. (2006), Luck et al. (2009), Flocks et al. (2011), and Zhou and Kim (2013) found a negative relationship between canopy cover and minority populations; Heynen and Lindsey (2003) found increased canopy cover associated with higher levels of educational attainment and older housing stock; and Donovan et al. (2011) found increased canopy cover within $50 \mathrm{~m}$ of a house to be associated with improved birth outcomes for non-Hispanic white women.

Street trees (i.e., trees growing in a street rightof-way) represent a minority of the overall urban forest (Dwyer et al. 2000). However, because of their public function-they are generally planned and managed by municipalities and are typically the urban trees with which most urban residents have the most frequent contact-street trees have often received particular attention (Cumming et al. 2008). In studying the spatial distribution of street trees, researchers have employed various metrics. In Tampa, Florida, U.S., Landry and Chakraborty (2009) differentiated street tree canopy cover from urban forest canopy cover and found less street tree canopy cover to be correlated with higher proportions of African-American residents, lower 
median household income, and lower proportions of owner-occupied housing. More typically, researchers have utilized street tree density (i.e., the number of street trees per unit street length or per unit area) as a metric in their studies. For example, in considering street trees as a pedestrian amenity affecting pedestrian behavior, the GIS (Geographic Information Systems) protocols of the Twin Cities Walking Study (2007) calculated a street tree density measure based on the number of street trees per summed street length contained within an area; in exploring possible relationships between street trees and childhood asthma in New York City, New York, U.S., Lovasi et al. (2008) calculated a street tree density measure based on the total number of street trees contained within hospital catchments divided by the areas of those catchments; and in associating street tree prevalence with lower body mass index, Lovasi et al. (2012) evaluated the number of street trees within $1 \mathrm{~km}$ network buffers. Additional metrics based on a street tree count have included street trees per capita, or the number of street trees in an area divided by the area's population (McPherson and Rowntree 1989), and stocking level, or the number of street trees planted as a percentage of all available planting sites, whether those sites contain trees or not.

Metrics based on a street tree count require that street trees have been geo-referenced (i.e., assigned longitude and latitude coordinates), using either GPS (Global Positioning System) equipment or a street address locator (geocoding). Such metrics make the assumption that all trees function equally regardless of species type and size. This assumption may be significantly flawed. For example, Donovan and Prestemon (2012) found that larger street trees with higher crowns were associated with decreased crime occurrence in Portland, Oregon, U.S. Similarly, since most ecosystem services provided by trees are proportional to the amount of leaf surface area, larger statured tree species typically provide many more of these services than smaller statured street tree species (Nowak et al. 2002; Sydnor and Subburayalu 2011). Therefore, accurately analyzing the spatial distribution of street trees and the benefits they provide may necessitate moving beyond metrics based on a street tree count, such as street tree density, and toward metrics that factor tree species and tree size into their calculation.

\section{i-Tree}

The United States Forest Service developed the i-Tree suite of computer software programs to quantify benefits provided by urban trees. These programs include Eco (previously named UFORE) and Streets (previously, STRATUM). i-Tree Streets was created expressly for street trees and quantifies the annual benefits provided by street trees in five categories: energy conservation, air quality improvement, $\mathrm{CO}_{2}$ reduction, stormwater mitigation, and property value increase (USDA Forest Service 2011). For example, stormwater benefits are determined by the annual precipitation (measured in gal.) intercepted by trees multiplied by the price (per gal.) required to treat and control runoff to meet minimum standards (McPherson et al. 2007). For Streets to quantify benefits, tree species and trunk diameter data must be collected for each tree surveyed. Benefits can be calculated from a complete inventory where data are collected from all street trees in a municipality or neighborhood or from a sample inventory where data are collected according to a sampling methodology (i.e., stratified by land use, 2,000 to 2,200 tree minimum) devised by Jaensen et al. (1992).

Limitations inherent in the methods and models underlying benefit calculations must be acknowledged. For example, leaf area for each tree species is estimated from computer processing of tree-crown imagery, a technique whose accuracy has been found to be $\pm 20 \%$ of actual leaf area (Peper and McPherson 2003); leaf area for each tree species as predicted by trunk diameter data is based on best-fit statistical modeling (Peper et al. 2001), which depends in turn on data collected from a representative set of street trees stratified by size (small, medium, large) and type (deciduous, evergreen) and is randomly sampled in a reference city within an i-Tree climate zone. Reliance on a reference city within an i-Tree climate zone is a particular concern (McPherson 2010). For example, the reference city for i-Tree's northeast climate zone is the borough of Queens in New York City, and the reference city for i-Tree's Midwest climate zone is Minneapolis, Minnesota; the modeling results from each reference city are extrapolated to other municipalities within the same climate zone (Peper et al 2001). Although benefit estimate inputs, such as the cost per gallon required to treat and control runoff, can be customized in Streets, relying on statistical modeling based on ref- 
erence city data is, as McPherson (2010) admits, a poor substitute for modeling based on local data, and extrapolating modeling results from Queens to Buffalo, New York, or from Minneapolis to Fort Wayne, Indiana, can reduce estimate accuracy and validity. Nevertheless, while recognizing these limitations, Streets accounts for differences in street tree benefits accrued from differences in leaf surface area while metrics based on a street tree count do not.

However, Streets is not a GIS program and does not provide spatial analysis of street tree benefits. Additionally, Streets does not generate benefit estimates for each individual street tree, but aggregates estimates for all street trees located within a user-defined zone, such as a municipality, neighborhood, or management unit. Therefore, to use Streets for the spatial analysis of street tree benefits, methods must be utilized in which Streets benefit estimates are referenced geographically so that user-defined zones in Streets correspond to the areas of the variables with which they are being correlated. For example, if street tree benefits are being correlated with race or owner-occupied housing, which are variables associated with United States Census Bureau blocks, user-defined zones in Streets must correspond to block boundaries. Similarly, if street tree benefits are being correlated with median household income or educational attainment, which are variables associated with Census Bureau block groups, user-defined zones in Streets must correspond to block-group boundaries.

\section{METHODS}

The following steps illustrate a case in which street tree benefit estimates generated by i-Tree Streets are correlated with median household income data associated with block groups in a municipality. As stated, street trees and the benefits they provide must be correctly assigned to block groups, not a small task, when thousands or tens of thousands of street trees are involved and can be accomplished using a GIS program.

Street tree inventory data from 2007 was obtained for Providence, Rhode Island, U.S. The data set consisted of more than 27,000 trees. Data for each inventoried tree included genus, species, $\mathrm{DBH}$, and longitude and latitude coordinates. Next, a 2010 TIGERLine (Topologically Integrated Geographic Encoding and Referencing) block-group boundary shapefile for the 2000 Census was obtained from the U.S. Census Bureau (U.S. Census 2011a; U.S. Census 2011b). Since the implementation of the Census Bureau's MAF/TIGER Accuracy Improvement Project (MTAIP) in 2002, and the release of MTAIP shapefiles in 2009, census geographic area boundaries and "local" street centerlines generally, but not always, conflate (i.e., line up), an important consideration since street tree locations are typically geo-referenced to local street centerlines.

After verifying that block-group boundaries lined up accurately with street centerlines, street tree data were assigned to block groups in GIS. Different options were available depending on the GIS program. For example, in ArcGIS, this can be done via a Spatial Join. In Manifold GIS, this can be done using an SQL statement. Whichever program or operation the user chooses, species and $\mathrm{DBH}$ data for each tree in the dataset must be associated with their respective block group because Streets requires species and $\mathrm{DBH}$ data a minimum to generate benefit estimates for each inventoried tree,. Additionally, each block group must be uniquely identified in such a way that benefits generated by Streets for each user-defined zone (in this example the block group) can later be joined with blockgroup data variables, such as median household income. Unique identifiers can include an STFID or GEOID code (a concatenation of codes for the state, county, tract, and block group). The STFID code was used in this case. Benefit estimates were generated in Streets for each block group. Benefit density was calculated by dividing benefits per block group by total street length associated with each block group. This was done because block groups vary by size and the amount of street length associated with each block group tends to vary proportionately. It is also consistent with methods employed by Lovasi et al. (2008). Summed street length for each block group was calculated using GIS. Benefit density values were then joined to a table containing median household income using the block group STFID code as the target column to match.

To facilitate comparison with the benefit density variable, street tree counts and street tree density values were calculated for each block group using methods similar to those just described. Street tree density values were joined to the table already containing median household income values and benefit density 
values for each block group, again using the block group STFID code as the target column to match.

Next, the table containing these variables and block-group STFID codes was joined to a blockgroup shapefile and imported into GeoDA (Anselin et al. 2006), a software program facilitating spatial data analyses. All variables were analyzed in GeoDA for spatial autocorrelation, a measure of association based on distance in Euclidean space that is considered a potentially confounding factor in spatial statistics. Moran's I is an established statistic of spatial autocorrelation and quantifies the correlation between a variable $\mathrm{X}$ and its spatial lag, the mean value of variables similar to variable $\mathrm{X}$ near to variable X (Bolstad 2005). Moran's I was calculated for each variable based on 1st order neighbors with Queen contiguity. Statistically significant levels of spatial autocorrelation were found for all variables. Bivariate correlations of benefit density with median household income and street tree density with median household income revealed that a weight matrix of 3rd order neighbors with Queen contiguity best reduced spatial autocorrelation for benefit density and a weight matrix of 4th order neighbors with Queen contiguity best reduced spatial autocorrelation for street tree density. Regressions were then run in GeoDA using these weight matrices.

\section{RESULTS}

OLS regressions were run in GeoDA in which median household income was regressed on benefit density and street tree density. Results for both regressions indicated statistical significance $(\alpha=$ 0.05 ) for median household income as a predictor variable (Table 1). Residuals were found to be normally distributed (Jarque-Bera test) and did not show significant heteroskedasticity (BreuschPagan and Koenker-Bassett tests) or spatial autocorrelation (Moran's I). Results also indicated a stronger statistical relationship between median household income and benefit density than between median household income and street tree density.

Additional OLS regressions were run in GeoDA using the weight matrices previously specified for other block-group census variables: percent white population, percent black population, percent occupied housing, percent B.A. educational attainment, and median value of owner-occupied housing. Most of these variables were used in the previously mentioned studies that associate urban tree distribution with socioeconomic factors. Results (Table 1) indicate a stronger statistical relationship for all variables with benefit density than with street tree density. Percent B.A. educational attainment was found to have the most explanatory power among all variables, including median household income.

OLS regression models using the weight matrices specified were run for benefit density and street tree density employing the block-group census variables. A model containing percent B.A. educational attainment and percent occupied housing offered a slightly better fit for benefit density $\left(r^{2}=0.419, \alpha=0.05\right.$, Prob $>F=<0.0001)$ than a model containing percent B.A. educational attainment and median household income $\left(r^{2}=0.405\right)$. Problems with multicollinearity were not found. Neither model was found to be statistically significant for street tree density.

\section{DISCUSSION}

Results indicate that statistically significant relationships exist, first, between street tree density and census block-group variables. These results are not surprising since they are similar to those cited in other studies (Landry and Chakraborty 2009; Neckerman et al. 2009). Second, results indicate that statistically significant relationships exist between street tree benefit density and block-group variables. Again, these results are not surprising since, in Providence at the block-group level, benefit density is highly correlated with street tree density $(r=0.93)$,

Table 1. OLS regression statistics in GeoDA employing weight matrices to account for spatial autocorrelation ( $\alpha=0.05$, $n=162$ ).

\begin{tabular}{lllll}
\hline & \multicolumn{2}{c}{ Benefit density } & & \multicolumn{2}{c}{ Tree density } \\
\cline { 2 - 3 } & $r^{2}$ & Prob $>\mathrm{F}$ & $r^{2}$ & 0.179 \\
Median household income & 0.267 & $<0.0001$ & $<0.0001$ \\
Median value owner-occupied housing & 0.210 & $<0.0001$ & 0.165 & $<0.0001$ \\
Percent B.A. educational attainment & 0.389 & $<0.0001$ & 0.333 & $<0.0001$ \\
Percent black population & 0.080 & 0.0003 & 0.032 & 0.0233 \\
Percent occupied housing & 0.097 & 0.0001 & 0.034 & 0.0193 \\
Percent white population & 0.190 & $<0.0001$ & 0.085 & 0.0002 \\
\hline
\end{tabular}


and the spatial distribution of benefit density closely approximates that of street tree density (Figure 1). Nevertheless, a comparison of z-scores for benefit density and street tree density distributed by block groups does show areas in which benefit density and street tree density differ appreciably (Figure 2). Third, results indicate that statistical relationships between benefit density and the block-group variables employed in this case study are stronger than the relationships between these variables and street tree density. The differences in these relationships are not dramatic. They do not suggest that measures based on street tree counts should be abandoned in the spatial analysis of municipal street trees. As previously stated, street tree density may be highly correlated with benefit density, especially at the blockgroup level, where meaningful differences found for individual street segments comparable to those identified by Sydnor and Subburayalu (2011) are likely to be smoothed out. The census block group was selected as the level of analysis because it is the smallest geographic area at which many socioeconomic variables such as median household income are available. If a municipality possesses socioeco- nomic data at a smaller level of analysis, such as a neighborhood, the methods described in this paper can be applied to that level as long as boundaries line up accurately with street centerlines.

A meaningful limitation to the methods outlined in this paper is that i-Tree Streets can only analyze 20 user-defined zones, such as census blocks or block groups, at one time. In the 2000 Census, Providence contained 162 block groups and more than 2,000 blocks. An analysis of 162 block groups in Streets requires 9 iterations of the program, while analyzing more than 2000 blocks requires at least 100 iterations. Measures based on street tree counts are typically quicker and easier to calculate, particularly at more discrete geographic levels, where the number of geographic units requiring analysis is large, such as the census block. Additionally, as was previously noted, significant limitations exist in the methods and models underlying benefit calculations generated by i-Tree. Consequently, benefit estimates may be less precise than counts of trees derived from a complete street tree inventory.

However, findings made by Nowak et al. (2002), Sydnor and Subburayalu (2011), and Dono-

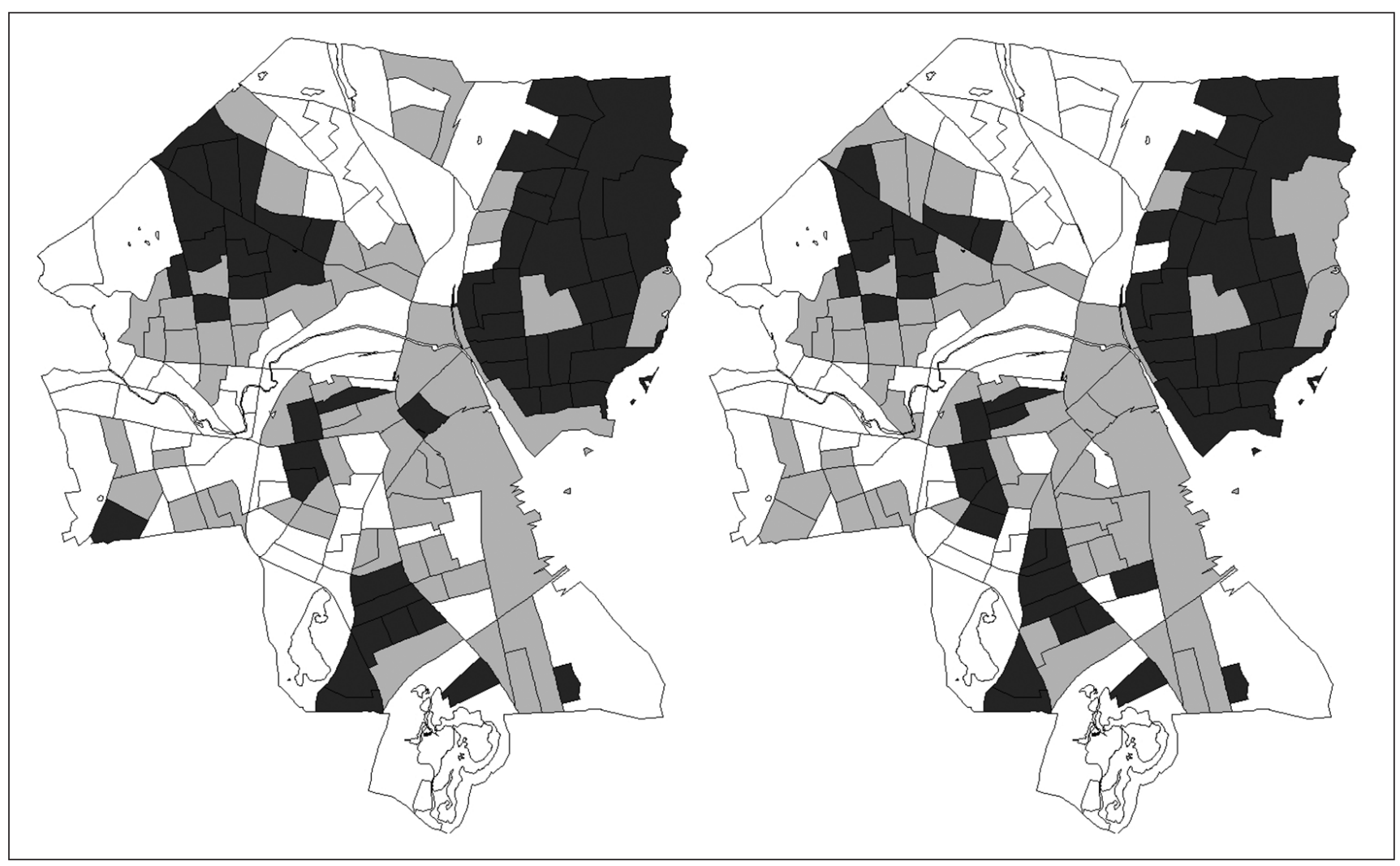

Figure 1. Spatial distribution of Benefit Density (left) and Street Tree Density (right), in Providence, Rhode Island, U.S. Values are apportioned equally to three subsets. Darker shading indicates larger values. 


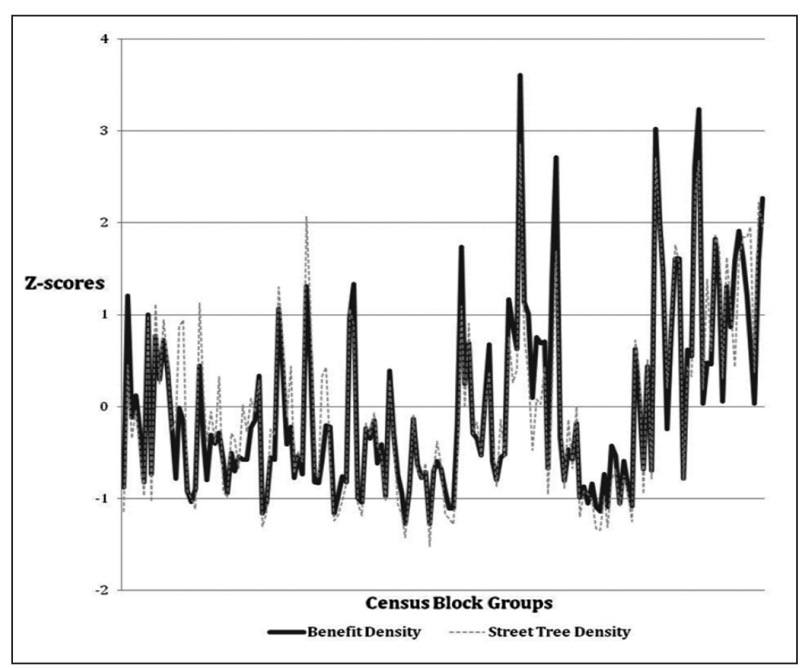

Figure 2. Benefit Density and Street Tree Density z-scores for Providence block groups in the 2000 U.S. Census.

van and Prestemon (2012) have established that not all street trees function equally, regardless of species type and size. In particular, larger statured street tree species generally provide many more ecosystem services than smaller statured street tree species. The role played by street trees in providing these services is increasingly seen by municipalities as important (Seamans 2013).

Therefore, if understanding relative street tree function and performance in a spatial context is desired, then measures incorporating benefit estimates should be considered in addition to measures based on tree counts when analyzing the spatial distribution of municipal street trees.

\section{LITERATURE CITED}

Anderson, L.M., and H.K. Cordell. 1988. Influence of trees on residential property values in Athens, Georgia (USA): A survey based on actual sales prices. Landscape and Urban Planning 15:153-164.

Anselin, L., I. Syabri, and Y. Kho. 2006. GeoDa: An introduction to spatial data analysis. Geographical Analysis 38:5-22.

Bolstad, P. 2005. GIS Fundamentals. 2nd Edition. Eider Press: Minnesota.

Cavanagh, J.E., P. Zawar-Reza, and J.G. Wilson. 2009. Spatial attenuation of ambient particulate matter air pollution within an urbanized native forest patch. Urban Forestry \& Urban Greening 8:21-30.

Cumming, A.B., D.B. Twardus, R. Hoehn, D.J. Nowak, M. Mielke, R. Rideout, H. Butalla, and P. Lebow. 2008. Wisconsin Street Tree Assessment 2002-2003. USDA Forest Service, Northeast Area State and Private Forestry, NA-FR-02-08, December 2008. Accessed 01/20/2012. <http://na.fs.fed.us/pubs/fhm/street_ trees/wi_street_tree_assessment_hr.pdf $>$

Donovan, G.H., and J.P. Prestemon. 2012. The effect of trees on crime in Portland, Oregon. Environment and Behavior 44:3-30.
Donovan, G.H., Y.L. Michael, D.T. Butry, A.D. Sullivan, and J.M. Chase. 2011. Urban trees and the risk of poor birth outcomes. Health \& Place 17:390-393.

Dwyer, J.F, D.J. Nowak, M.H. Noble, and S.M. Sisinni. 2000. Connecting people with ecosystems in the 21st century: An assessment of our nation's urban forests. Gen. Tech. Rep. PNWGTR-490. Portland, OR: U.S. Department of Agriculture, Forest Service, Pacific Northwest Research Station. 483 pp. Accessed 04/05/2012. <www.ncrs.fs.fed.us/pubs/2517>

Escobedo, F., D.J. Nowak, J. Wagner, J., C.L. Dela Maza, M. Rodríguez, D.E. Crane, and J. Hernández. 2006. The socioeconomics and management of Santiago de Chile's public urban forests. Urban Forestry \& Urban Greening 4:105-114.

Flocks, J., F. Escobedo, J. Wade, S. Varela, and C. Wald. 2011. Environmental justice implications of urban tree cover in Miami-Dade County, Florida. Environmental Justice 4:125-134.

Giles-Corti, B., and R.J. Donovan. 2003. Relative influences of individual, social, environmental, and physical environmental correlates of walking. American Journal of Public Health 93:1583-1589.

Heynen, N., H.A. Perkins, and P. Roy. 2006. The political ecology of uneven urban green space: The impact of political economy on race and ethnicity in producing environmental inequality in Milwaukee. Urban Affairs Review 42:3-25.

Heynen, N.C., and G. Lindsey. 2003. Correlates of urban forest canopy cover: Implications for local public works. Public Works Management \& Policy 8:33-47.

Iverson, L.R., and E.A. Cook. 2000. Urban forest cover of the Chicago region and its relation to household density and income. Urban Ecosystems 4:105-124.

Jaensen, R., N. Bassuk, S. Schwager, and D. Headley. 1992. A statistical method for the accurate and rapid sampling of urban street tree populations. Journal of Arboriculture 18:171-183.

Jennings, S.B., N.D. Brown, and D. Sheil. 1999. Assessing forest canopies and understory illumination: Canopy closure, canopy cover and other measures. Forestry 72:59-73.

Kuo, F.E. 2003. The role of arboriculture in a healthy social ecology. Journal of Arboriculture 29:148-155.

Landry, S.M., and J. Chakraborty. 2009. Street trees and equity: Evaluating the spatial distribution of an urban amenity. Environment and Planning A 41:2651-2670.

Lovasi, G.S., J.W. Quinn, K.M. Neckerman, M.S. Perzanowski, and A. Rundle. 2008. Children living in areas with more street trees have lower prevalence of asthma. Journal of Epidemiology and Community Health 62:647-649.

Lovasi, G.W., M. Bader, J. Quinn, K. Neckerman, C. Weiss, and A. Rundle. 2012. Body mass index, safety hazards, and neighborhood attractiveness. American Journal of Preventive Medicine 43:378-384

Luck, G.W., L.T. Smallbone, and R. O’Brien. 2009. Socio-economics and vegetation change in urban ecosystems: Patterns in space and time. Ecosystems 12:604-620.

Lynn, B.H., T.N. Carlson, C. Rosenzweig, R. Goldberg, L. Druyan, J. Cox, S. Gaffin, L. Parshall, and K. Civerolo. 2009. A modification to the NOAH LSM to simulate heat mitigation strategies in the New York City metropolitan area. Journal of Applied Meteorology and Climatology 48:199-216.

McPherson, E.G., and R.A. Rowntree. 1989. Using structural measures to compare twenty-two U.S. street tree populations. Landscape Journal 8(1):13-23. 
McPherson, E.G. 2010. Selecting reference cities for i-Tree Streets. Arboriculture \& Urban Forestry 36:230-240.

McPherson, E.G., J.R. Simpson, P.J. Peper, S.L. Gardner, K.E. Vargas, and Q. Xiao. 2007. Northeast community tree guide: Benefits, costs, and strategic planting. Gen. Tech. Rep. PSW-GTR-202. Albany, CA: U.S. Department of Agriculture, Forest Service, Pacific Southwest Research Station: 106 p. Accessed 03/18/ 2011. $<$ www.fs.fed.us/psw/publications/documents/psw_gtr202/ psw_gtr202.pdf>

Neckerman, K.M., G.S. Lovasi, S. Davies, M. Purciel, J. Quinn, E. Feder, N. Raghunath, B. Wasserman, and A. Rundle. 2009. Disparities in urban neighborhood conditions: Evidence from GIS measures and field observation in New York City. Journal of Public Health Policy 30(S1):S264-S285.

Nowak, D.J., D.E. Crane, J.C. Stevens, and M. Ibarra. 2002. Brooklyn's Urban Forest. General Technical Report NE-290, USDA Forest Service, Northeastern Research Station. 107 p. Accessed 03/02/2011. <www.fs.fed.us/ne/newtown_square/publications/ technical_reports/pdfs/2002/gtrne290.pdf>

Peper, P.J., and E.G. McPherson. 2003. Evaluation of four methods for estimating leaf area of isolated trees. Urban Forestry \& Urban Greening 2:19-29.

Peper, P.J., E.G. McPherson, and S.M. Mori. 2001. Predictive equations for dimensions and leaf area of coastal Southern California street trees. Journal of Arboriculture 27:169-180.

Pham, T., P. Apparicio, A. Seguin, S. Landry, and M. Gagnon. 2012. Spatial distribution of vegetation in Montreal: An uneven distribution or environmental inequity? Landscape and Urban Planning 107:214-224.

Seamans, G.S. 2013. Mainstreaming the environmental benefits of street trees. Urban Forestry \& Urban Greening 12:2-11.

Sydnor, T.D., and S.K. Subburayalu. 2011. Should we consider expected environmental benefits when planting larger or smaller tree species? Arboriculture \& Urban Forestry 37:167-172.

Talarchek, G.M. 1990. The urban forest of New Orleans: An exploratory analysis of relationships. Urban Geography 11:65-86.

Twin Cities Walking Study. 2007. Environment and Physical Activity: GIS Protocols Version 4.1, June 2007, Work in Progress. A. Forsyth (Ed.). Accessed 07/13/2010. <www.designforhealth. net/resources/gis_protocols.html>

United States Census Bureau. 2011a. Geographic Terms and Concepts - Block Group. Accessed 05/14/2012. <www.census. gov/geo/www/2010census/gtc/gtc_bg.html>

United States Census Bureau. 2011b. TIGER FAQs. Accessed 10/31/2011. <www.census.gov/geo/www/tiger/shp.html>

USDA Forest Service. 2011. i-Tree Streets. Accessed 08/11/2011. $<$ www.itreetools.org/streets/index.php>

Xiao, Q., E.G. McPherson, J.R. Simpson, and S.L. Ustin. 1998. Rainfall interception by Sacramento's urban forest. Journal of Arboriculture 24:235-244.

Zhou, X. and J. Kim. 2013. Social disparities in tree canopy and park accessibility: A case study of six cities in Illinois using GIS and remote sensing. Urban Forestry \& Urban Greening 12:88-97.

\author{
F.D. Cowett \\ Post-doctoral Associate \\ Department of Horticulture \\ Cornell University \\ 134 Plant Sciences Bldg. \\ Ithaca, New York 14853, U.S. \\ fdc2@cornell.edu
}

Zusammenfassung. Straßenbäume stellen eine Fraktion der urbanen Forste dar; dennoch, wegen ihrer öffentlichen Funktion, die Vorteile die Bäume für die urbanen Bewohner liefern haben das besondere Interesse von Forschern geweckt. Flächendeckende Analysen von Vorteilen von Straßenbäumen basierten auf Straßenbaumzählungen, die nicht für die Differenzen bei den Baumarten und Größen zählen, die im Gegenzug die Blattfläche beeinflussen, von der die meisten Vorteile herstammen. Das United States Forest Service's i-Tree Streets software program quantifiziert Straßenbaumvorteile und zählt nicht für die Differenzen bei den Baumarten und Größen, aber es ist kein Geographic Information Systems Programm und erleichtert nicht die flächendeckende Analyse von Vorteilen von Straßenbäumen. Diese Studie schlägt eine Methodologie für die Analyse der flächendeckenden Verteilung von Vorteilen durch Straßenbäume, unter der Einbindung der Messungen mit iTree Streets. Vorausschauend dient RI als eine Fallstudie.

Resumen. Los árboles en las calles comprenden una fracción del bosque urbano debido a su función pública y los beneficios que proporcionan a los residentes han sido objeto de especial atención por parte de los investigadores. Los análisis espaciales de los beneficios de los árboles urbanos se han basado en el recuento de los mismos. Sin embargo, estos análisis no dan cuenta de las diferencias en especies y el tamaño de la superficie foliar, de donde se derivan la mayoría de estos beneficios. El programa de software Forest Service's i-Tree Streets del Servicio Forestal de los Estados Unidos cuantifica los beneficios de los árboles de la calle y da cuenta de las diferencias en la especie y el tamaño de los árboles, pero no es un Sistema de Información Geográfica y no facilita el análisis espacial de los beneficios de los árboles urbanos. En este trabajo se propone una metodología para el análisis de la distribución espacial de los beneficios de los árboles urbanos empleando mediciones sobre la base de i-Tree Streets en Providence, RI, que sirve como caso de estudio. 